* Mestranda na Área de Direito Comercial da Universidade do Estado do Rio de Janeiro

E-mail: laurasoaresm15@ gmail.com

** Doutor em Saúde Pública pela Escola Nacional de Saúde Pública Sérgio Arouca da Fundação Oswaldo Cruz Professor do Programa de PósGraduação em Direito e da Graduação da Faculdade de Direito da Universidade do Estado do Rio de Janeiro E-mail: lsantanna44@gmail.com

\section{DEVERES E RESPONSABILIDADES DOS ADMINISTRADORES DE SOCIEDADES ANÔNIMAS E O BUSINESS JUDGMENT RULE NO BRASIL}

\section{DUTIES AND RESPONSIBILITIES OF DIRECTORS OF JOINT STOCK COMPANIES AND THE BUSINESS JUDGMENT RULE IN BRAZIL}

Laura Soares Miranda dos Santos*
Leonardo da Silva Sant'Anna **

Como citar: SANTOS, Laura Soares Miranda; SANT'ANNA, Leonardo da Silva. Deveres e responsabilidades dos administradores de sociedades anônimas e o business judgment rule no Brasil. Scientia luris, Londrina, v. 25, n. 3, p. 10-24, nov. 2021. DOI: 10.5433/21788189.2021v25n3p10. ISSN: 2178-8189.

Resumo: O presente estudo pretendeu examinar a concepção da técnica de julgamento alienígena denominada Business Judgment Rule e a possibilidade de sua aplicação no ordenamento jurídico brasileiro. A análise partiu da observação de como a Lei $\mathrm{n}^{\circ} 6.404 / 1976$ (LSA) define os direitos e responsabilidades dos administradores de uma sociedade anônima, seguida por uma breve revisão de literatura sobre o assunto, realizou-se então um estudo sobre os precedentes desta técnica de julgamento na Comissão de Valores Mobiliários (CVM) e, a partir disso, foi possível descrever, em linhas gerais, porém sem esgotar o assunto, como a CVM interpreta o art. $159, \S 6^{\circ}$ da LSA.

Palavras-chave: Business Judgment Rule. Direito societário.

\begin{abstract}
This study aimed to examine the conception of the alien judgment technique called Business Judgment Rule and the possibility of its application in the Brazilian legal system. The analysis was based on the observation of how Law $n^{\circ} 6.404 / 1976$ (LSA) defines the rights and responsibilities of the administrators of a corporation, followed by a brief literature review on the subject, precedents of this judgment technique in the Brazilian Securities Commission (CVM) and, from this, it was possible to describe, in general, but without exhausting the subject, how the CVM interprets art. $159, \S 6$ of the LSA.
\end{abstract}

Keywords: Business Judgment Rule. Corporate law. 


\section{INTRODUÇÃO}

O estudo das sociedades anônimas é rico em nuances sobre a multiplicidade de aspectos inerentes a sua natureza. Esse trabalho propõese a abordar a temática das responsabilidades e deveres atribuídos pela lei aos administradores das companhias, pessoas físicas que são investidas e tomam posse em cargos gerenciais, a fim de dar voz a personalidade jurídica da pessoa jurídica que é a sociedade empresária.

Os administradores, por não poderem exercer livremente sua vontade pessoal, uma vez que presentam a sociedade, precisam ser cautos ao manifestarem os atos negociais, observando as diretrizes legais, como os deveres de diligência, sigilo e lealdade ${ }^{1}$, além de agirem de acordo com o conceito dos atos regulares de gestão.

De acordo com os autores Lamy Filho e Bulhões Pedreira, a importância da atuação dos administradores está diretamente ligada ao sucesso ou ao fracasso do exercício da atividade econômica da companhia:

$\mathrm{Na}$ estrutura da companhia, cabe uma referência especial aos órgãos da administração e às pessoas que os integram, que respondem pelo sucesso ou insucesso da empresa. Reunindo capitais de inúmeras procedências, e número ilimitado de acionistas, o problema da administração da companhia reveste sempre complexidade que não encontra solução em texto de lei ou de norma disciplinar, mas sim na eficiência dos que a exercem. (BULHÕES PEDREIRA; LAMY FILHO, 2017, p. 575)

Seu objetivo, ao agirem, deve ser sempre o interesse da companhia e jamais seus interesses pessoais. Ao operarem em um meio inerente ao risco, devem saber orientar-se a fim de se resguardarem não de más decisões que resultem prejuízo, mas sim, de decisões desinformadas, negligentes e descompromissadas que resultem em dano patrimonial à sociedade.

Para além desses aspectos, a análise de uma técnica de julgamento originária da jurisprudência norte americana, denominada de Business Judgment Rule, apresenta-se como um pressuposto de idoneidade nos atos negociais nos julgados cujo mérito destrincha a responsabilização dos tomadores de decisões negociais dentro do Common Law no Estados Unidos e a hesitação se há possibilidade de sua aplicação no ordenamento jurídico brasileiro, a partir da interpretação da própria legislação societária 1 Artigos 153 a 157 da Lei n 6.404/1976 (BRASIL, 1976b). 
nacional, sem olvidar o caráter positivista do sistema brasileiro são os aspectos que serão explorados visando a reflexão se é viável a utilização dessa técnica alienígena nas ações de responsabilidade e nos processos administrativos sancionadores julgados no Brasil.

A metodologia adotada é de revisão bibliográfica sobre o tema da responsabilização dos administradores de sociedades anônimas de acordo com a Lei brasileira de sociedades por ações e a aplicação da técnica de julgamento estrangeira denominada Business Judgment Rule no ordenamento jurídico brasileiro, além da exposição de casos concretos julgados pela Comissão de Valores Mobiliários, autarquia responsável pela fiscalização das atividades exercidas pelas companhias abertas ${ }^{2}$, em 2018, que ratificam a aplicação da técnica jurisprudencial ao contexto brasileiro.

\section{A ADMINISTRAÇÃO DAS COMPANHIAS}

As sociedades anônimas, também chamadas de companhias, são definidas no artigo $1^{\circ}$ da Lei 6.404/76, a Lei de Sociedades por Ações (LSA) e pelo artigo 44, II do Código Civil, como pessoa jurídica de direito privado com capital dividido em ações e cuja responsabilidade dos sócios será limitada ao preço de emissão das ações subscritas ou adquiridas. É também o Código Civil que define a sociedade anônima como sociedade empresária, por ser uma sociedade por ações 3 .

Sendo, portanto, empresária a sociedade, seu objeto é o exercício de atividade econômica organizada para a circulação e produção de bens e serviços. Tal arranjo demanda uma organização própria, composta de agentes separados em suas atribuições a fim de permitir a vigência dessa estrutura.

A divisão, portanto, é feita entre órgãos, os chamados órgãos sociais. Os órgãos são centros de poderes funcionais, compostos de indivíduos, pessoas naturais, que foram investidos em seus cargos, a fim de manifestarem e formarem a vontade social, ou seja, a vontade da própria companhia, que, enquanto pessoa jurídica dotada de personalidade jurídica, a partir da inscrição de seus atos constitutivos, requer quem exteriorize sua vontade por meio do fenômeno da presentação.

A estruturação orgânica decorre da escolha da legislação e a cada órgão são atribuídas funções próprias e indelegáveis, sendo eles caracterizados de maneira hierárquica, Lamy Filho e Bulhões Pedreira salientam que "O poder hierárquico, próprio desse tipo de estrutura, é a capacidade de determinar e fiscalizar a ação ou comportamento dos ocupantes do órgão ou cargo subordinado" (BULHÕES PEDREIRA; LAMY FILHO, 2017, p. 564). De acordo com a LSA, são necessariamente imprescindíveis três órgãos, a Assembleia Geral, o Conselho Fiscal e a Diretoria, caso a companhia tenha previsto em seu estatuto social capital autorizado ou, se for companhia aberta ou de economia mista, também é obrigatório o Conselho de Administração.

O Conselho de Administração e a Diretoria são órgãos típicos de gestão, enquanto que a Assembleia Geral representa a reunião dos sócios, que definem, em conjunto, as diretrizes sociais 2 Artigo $8^{\circ}$, Inciso III, da Lei ${ }^{\circ} 6.385 / 1976$. (BRASIL, 1976a).

3 Artigo 982, Parágrafo Único, Código Civil (BRASIL, 2002). 
que deverão ser implementadas pelos administradores, membros do Conselho ou da Diretoria. Por sua vez, o Conselho Fiscal possui função de fiscalizar os atos praticados pelos administradores e a função de opinar sobre os assuntos deliberados nas Assembleias.

São, portanto, os órgãos de administração que merecem destaque ao se estudar a responsabilidade e deveres dos administradores, uma vez que o campo de sua atuação é dentro desses órgãos, o professor Tavares Borba elucida que "Os órgãos administrativos são os que dão vida à sociedade, fazendo-a funcionar. São dois esses órgãos: o conselho de administração e a diretoria." Como regra, as normas que regulam os deveres e responsabilidades dos administradores são aplicadas aos conselheiros e diretores ${ }^{4}$, visto que compõem os "órgãos executivos a que compete administrar os negócios sociais, realizando o objeto da sociedade dentro das normas traçadas pela assembleia” (MARTINS, 2017, p. 295).

O Conselho de Administração não é um órgão obrigatório em todas as espécies societárias, apenas nas companhias abertas, nas sociedades de economia mista e, naturalmente, nas sociedades de capital autorizado. Todavia, é possível a implementação desse órgão em qualquer sociedade, na finalidade de proporcionar maior eficiência, já que, ao lado da Diretoria, o Conselho de Administração terá funções diversas e ambos os órgãos trabalharão em harmonia na gerência da companhia.

Assim, o Conselho de Administração é identificado como um órgão colegiado, em que seus membros, os conselheiros, são indicados pela Assembleia Geral, órgão hierarquicamente superior, também colegiado, todavia composto pelos acionistas da companhia. As decisões do conselho de administração estão, majoritariamente, vinculadas à administração social, através da fixação das diretrizes negociais e a fiscalização dos diretores.

A Diretoria executiva, por sua vez, é um órgão de constituição obrigatória onde cada diretor possui atribuições próprias, podendo ou não existir a possibilidade de certas deliberações terem que ser realizadas em reuniões de diretoria, a critério do estatuto social. As ações individuais ou colegiadas dos membros da Diretoria são consideradas em matéria de responsabilização civil dos atos praticados em nome da sociedade, caso haja dano para a companhia.

A presentação da companhia é concretizada por meio da pessoa física dos diretores, são eles portando que assinam os contratos celebrados em nome da pessoa jurídica, e são também os diretores que efetivamente praticam todos os atos necessários ao regular funcionamento da sociedade.

A relevância da gerência social influenciou a LSA a permitir a criação de outros modelos de órgãos ${ }^{5}$ a fim de rebuscar a administração da companhia, assim, é possível que o estatuto social autorize a criação de conselhos consultivos, para que estes possam embasar as deliberações dos administradores. Então, é possível, por exemplo, que em uma companhia cujo objeto social esteja vinculado a construção civil, haja a existência de um comitê de engenharia civil para opinar e fundamentar as decisões que cabem aos administradores, já em uma outra voltada ao mercado publicitário, um grupo de especialistas em marketing e propaganda pode ser convocado para 
opinar em relação às decisões negociais dos diretores.

\section{OS DEVERES E AS RESPONSABILIDADES}

\subsection{OS DEVERES}

O comportamento dos administradores é norteado na Lei de Sociedades por Ações para guiar a atuação dos gestores em busca da melhor maneira de assumir riscos e enfrentar as adversidades do meio empresarial, uma vez que, aos administradores não é permitida uma atuação totalmente livre, estando eles vinculados ao interesse social da companhia. A maneira escolhida pela legislação é a fixação de padrões de comportamento acrescida da previsão de responsabilidades com a reparação civil nos casos de dano à pessoa jurídica.

Há, portanto, na lei a previsão de cláusulas gerais e também de cláusulas específicas que pautam os comportamentos que um gestor deve exercer ao se incumbir de sua função, a partir de sua nomeação, seja como membro da Diretoria Executiva, seja como membro do Conselho de Administração da sociedade. Enquanto o artigo 153 da LSA, que dispõe sobre o dever de diligência, determina que "O administrador da companhia deve empregar, no exercício de suas funções, o cuidado e diligência que todo homem ativo e probo costuma empregar na administração dos seus próprios negócios. " (BRASIL, 1976b), expondo uma orientação genérica, o §2, do artigo 154 apresenta vedações claras de comportamento ao ilustrar casos de desvio de poder.

Além das direções fornecidas pelos deveres legais, a conduta dos administradores apoia-se também no conceito de governança corporativa. A governança corporativa é um mecanismo utilizado para a difusão das técnicas de controle e transparência essenciais à atividade da administração. A companhia adere se quiser, porém, uma vez aderindo, está sujeita a ela. O Instituto Brasileiro de Governança Corporativa, o (IBGC), define governança corporativa da seguinte forma:

Governança corporativa é o sistema pelo qual as empresas e demais organizações são dirigidas, monitoradas e incentivadas, envolvendo os relacionamentos entre os sócios, conselho de administração, diretoria, órgãos de fiscalização e controle e demais partes interessadas. As boas práticas de governança corporativa convertem princípios básicos em recomendações objetivas, alinhando interesses com a finalidade de preservar e otimizar o valor econômico de longo prazo da organização, facilitando seu acesso a recursos e contribuindo para a qualidade da gestão da organização, sua longevidade e o bem comum. (INSTITUTO BRASILEIRO DE GOVERNANÇA CORPORATIVA, 2020)

Em relação aos deveres do gestor descritos na legislação, tais são enumerados de forma minuciosa entre os artigos 153 a 157 da LSA. Caracterizando-se por serem deveres de natureza fiduciária, ou seja, que aludem à confiança entre a função exercida e a sociedade. O mais importe dos deveres listados é o dever de diligência, podendo os demais serem considerados desdobramentos 
deste dever.

\subsubsection{O DeVER De DiLigênCIA}

Conforme já mencionado, o artigo 153 da LSA dispõe que "O administrador da companhia deve empregar, no exercício de suas funções, o cuidado e diligência que todo homem ativo e probo costuma empregar na administração dos próprios negócios”. (BRASIL, 1976b). Dessa premissa, extraem-se diversas considerações, como a possível crítica de que ao se cuidar de negócios de terceiros o zelo deveria ser maior do que o empregado ao próprio negócio. Porém, independente das críticas, a ponderação inicial é a de que o conceito de diligência foi feito de forma aberta, como sua própria intenção de cláusula geral demanda. A análise se houve ou não diligência no exercício da atuação é feita no caso concreto, onde são averiguadas variáveis como, o tipo de atividade exercida, os recursos que o gestor tinha ao seu dispor no momento que tomou aquela decisão, o momento e as circunstâncias da decisão e todas as particularidades inerentes à deliberação.

O dever de diligência é considerado o maior dos deveres, onde a obrigação do administrador é de meio e não de resultado, uma vez que o risco é inerente a atividade empresarial, sendo impossível afastá-lo. Assim é imprescindível a atuação atenta e precavida nas escolhas negociais.

O administrador é livre para decidir sobre a conveniência e oportunidade dos negócios sociais, podendo, naturalmente, ter sucesso ou não na sua decisão. De seu eventual erro ou insucesso na tomada de decisão não repercutirá qualquer responsabilidade, por quanto tenha decidido de maneira diligente, em boa-fé e naquilo que supôs ser o melhor interesse social. (BULHÕES PEDREIRA; LAMY FILHO, 2017)

A diligência enquanto dever legal possui cinco pilares que a sustentam, o dever de se informar, explorado pelo artigo 157, LSA; o dever de investigar; o dever de se qualificar; o dever de intervir e, por fim, a vigilância. Importante ressaltar que todas essas análises devem ser feitas pela ótica do procedimento e não do conteúdo da decisão, isso é sensível nas questões referentes aos conflitos de interesses.

Em suma, a decisão precisa ser informada, refletiva e desinteressada. Lembrando-se que o administrador defende os interesses da companhia, independente de quem o elegeu, se foi um acionista dentro do âmbito da Assembleia ou se foi trabalhador nos casos onde há essa possibilidade de escolha, Lamy Filho e Bulhões Pedreira lembram que:

ALei 10.303/2001 criou a possibilidade de os empregados elegerem representantes para o Conselho de Administração independentemente de serem acionistas: o parágrafo único do artigo 140 dispõe que 'o estatuto poderá prever a participação no conselho de representantes dos empregados, escolhidos pelo voto destes, em eleição direta, organizada pela empresa em conjunto com as entidades sindicais que o representem. (BULHÕES PEDREIRA; LAMY FILHO, 2017, p. 752) 


\subsubsection{O Dever de Lealdade e o Dever de Sigilo}

A lealdade é o segundo dever em importância e, novamente, da mesma forma que a diligência, é exercida em relação à companhia e não aos sócios, ou a quem tenha indicado o administrador a seu cargo.

Previsto no artigo 155, LSA, a lealdade tem implícitos deveres negativos, guardar reserva a respeito de seus negócios, ou seja, da forma como eles se encontram e suas intenções a respeito deles, caracteriza o dever de sigilo. O administrador, portanto, deve servir a companhia e não se servir dela para seus objetivos pessoais ou de terceiros.

A legislação societária aqui traz vedações expressas que configuram atos de deslealdade, em que há negligência ou apropriação no aproveitamento de oportunidades pela companhia. Em relação ao sigilo, nas companhias abertas há vedação expressa contra condutas de insider trading ${ }^{6}$, por exemplo.

\subsubsection{O DEVER DE INFORMAR}

Este dever, privativo de administradores de companhias abertas, está previsto no artigo 157, LSA e expressa a necessidade de conhecimento e veracidade que os administradores devem prestar aos acionistas da sociedade que ingressarão.

Isso posto, o momento que essas informações deverão ser prestadas é o da assinatura do termo de posse, onde essas informações serão relevantes para se acompanhar a mudança da posição do administrador frente à companhia.

\subsection{As RESPONSABILIDADES}

Na sequência dos deveres, a lei de sociedades anônimas dispõe sobre as responsabilidades dos administradores, nos parágrafos e caput do art. 158, LSA. A finalidade precípua da legislação societária ao manifestá-las não é a sanção, mas a reparação de danos. Razão pela qual, trata-se de um tema de responsabilidade civil, cujo foco encontra-se na recomposição patrimonial, isto é, o status quo antes.

A responsabilidade do administrador no direito societário pode ser resumida da seguinte forma: o prejudicado, a sociedade, o acionista ou terceiro, deve demonstrar a falta cometida pelo administrador, provando, inclusive, seu comportamento culposo ou doloso, ao agir dentro de suas atribuições e poderes ou ainda, na violação da lei ou estatuto social da companhia.

O administrador somente é preservado da responsabilização se tiver exercido os chamados atos regulares de gestão. É válido recordar que o administrador presenta a sociedade, quer dizer, ele exterioriza a vontade social, de forma que, para terceiros, é a própria sociedade, em decorrência 6 Artigo 155, $\S 1$ a $4^{\circ}$ da Lei nº 6.404/1976 (BRASIL, 1976b). 
do reconhecimento de sua personalidade jurídica, que assume as obrigações e exerce seus direitos. Portanto, não é possível querer se responsabilizar pessoalmente um administrador que agiu dentro dos parâmetros do ato regular de gestão ao presentar a sociedade. Caso algum terceiro se sinta prejudicado em razão de ato regular de gestão praticado por algum administrador, deve buscar responsabilizar a própria sociedade, pois, o administrador agiu em nome da pessoa jurídica, não cabendo, como já exposto, sua responsabilização pessoal, nesse caso.

No tocante ao aspecto do ato regular de gestão, sua definição não é precisa e demanda algumas ponderações. O comportamento dos administradores é pautado em padrões de conduta gerais e abstratos, de modo a evitar sua plena autonomia, com exceção de algumas vedações específicas previstas na lei conforme aqui exposto. A fim de se buscar delimitar essa expressão legal, a expressão oposta, qual seja, ato irregular de gestão, é analisada. O ato irregular de gestão é um conceito formado, da mesma forma, a partir, de sua definição legal, assim, a aferição da regularidade de determinado ato do gestor decorre da ofensa à lei ou ao estatuto social. Logo, havendo violação à lei ou ao estatuto por parte do administrador, há o pressuposto da irresponsabilidade.

No entanto, contrariamente, não basta esse limite, o gestor não pode agir livremente, evitando apenas ofender à lei ou o estatuto social. É de sua atribuição também, acatar aos, já vistos, deveres que a lei societária expõe, bem como, atualmente, a critérios determinados pelo conceito da, já vista, governança corporativa.

Assim sendo, diante do exposto sobre a responsabilidade, compete o estudo sobre as ações de responsabilidade apresentadas pela lei. É consagrado à companhia a ação social ut universi (LSA, art. 159, caput), que representa a ação da própria companhia contra os administradores. Tal decisão é fruto da soberania da Assembleia Geral, tratando-se de Assembleia Geral Ordinária, o assunto pode surgir ainda que não esteja previsto na ordem do dia, por outro lado, nas Assembleias Gerais Extraordinárias tal matéria deve estar prevista na ordem do dia ou então, desenrolar-se naturalmente em razão dos assuntos abordados naquela AGE.

De outra parte, a ação social ut singuli ocorre por intermédio dos acionistas, configurando uma hipótese de substituição processual, os sócios entram, em nome próprio, com a ação no interesse da companhia. É caso de substituição processual a fim de superar a inércia da sociedade ao deixar de propor a ação social ut universi.

A LSA dispõe de duas espécies de ação social ut singuli, respectivamente nos $\S \S 3^{\circ}$ e $4^{\circ}$, do art. 159, LSA. O primeiro caso é a ação social ut singuli por substituição processual derivada, que permite ao sócio ser autor da ação tendo decorrido três meses da data da Assembleia Geral sem que a sociedade tenha proposto a ação. $\mathrm{O}$ outro caso é o da ação social ut singuli por substituição processual originária, onde os sócios que representem cinco por cento ao menos do capital social podem propô-la caso a Assembleia decida por não o fazer.

Há também a previsão da ação individual para o tratamento do dano patrimonial individual, seja de sócio ou terceiro prejudicado diretamente pela tomada de decisão irresponsável do gestor da sociedade, aqui é claramente desnecessária a deliberação em Assembleia. Cumpre esclarecer que o terceiro não precisa ser credor da sociedade e que como o dano precisa ser direto, e não 
reflexo do dano causado à sociedade, sendo, portanto, rara sua aplicação na prática.

Resta presente, atualmente, o seguro de responsabilidade civil de administradores, conhecido como seguro D\&O (Director's and Officers) como instrumento que busca conciliar a assunção de riscos e tomada de decisões, inerentes à atividade empresarial, com a proteção à sociedade, sócios e terceiros dos atos irresponsáveis de gestão. A contratação do seguro é usualmente celebrada pela companhia através de apólice coletiva em favor dos administradores, visando a proteção do patrimônio social na ocorrência de eventuais efeitos econômicos negativos frutos da irresponsabilidade gerencial.

\section{O BUSINESS JUDGMENT RULE}

Após analisados os deveres e responsabilidades alusivos aos administradores, compete o estudo de um instituto de origem norte americana denominado Business Judgment Rule e sua pertinência dentro do ordenamento jurídico brasileiro nos casos de responsabilização.

Essa é uma regra de origem jurisprudencial que surgiu quando os tribunais norte americanos passaram a recusar a análise do mérito das decisões negociais sob o argumento de que sua análise deveria limitar-se a verificação, diante das particularidades do caso apreciado, se a tomada de decisão ocorreu seguindo o procedimento orientado pela legislação, ou seja, de forma razoável e bem informada, porém sem julgar a deliberação em si, exceto, é claro, nos casos em que foi tomada em desacordo com as orientações e, portanto, de forma equivocada (BRIGAGÃO, 2017).

Em outras palavras, os juízes norte-americanos passaram a decidir sob a orientação de uma regra, formulada por eles mesmos, na qual ao serem examinados casos de responsabilização administrativa, os administradores estariam protegidos em seu âmbito pessoal, e, portanto, isentos da obrigação reparatória, caso tenham tomado a decisão que desencadeou o processo de reparação e responsabilização, imbuídos de boa-fé, de forma diligente e visando atender os interesses da sociedade que presentavam.

Assim sendo, ao se utilizar essa regra, os administradores não são responsabilizados por prejuízos, mas sim por decisões desinformadas. Ao ser formulada e em sua aplicação, a regra detém a presunção de que os administradores sempre atuam diligentemente e no interesse da companhia ao exercer suas funções. Dessa forma, a proteção da regra compreende apenas decisões racionais, que não impliquem no desperdício de ativos da companhia. Por sua vez, não protege condutas fraudulentas, ilegais ou ultra vires.

A utilização dessa regra obrigou os julgadores a não mais verificarem os resultados decorrentes da decisão tomada pelos gestores, que se restringiam muito ao alcance do dano gerado, mas, de forma contrária, vinculou a análise da conduta do agente, buscando-se evidências de comportamentos negligentes e desassociados de sua função.

A Business Judgment Rule é, desta maneira, sintetizada em cinco características: (i) a 
ocorrência de uma decisão negocial; (ii) o desinteresse e independência na tomada dessa decisão; (iii) a diligência; (iv) a boa-fé e, por fim, (v) a inexistência de abuso. Decisões, portanto, informadas, refletidas e desinteressadas são prezadas por esta regra.

Vale ressaltar que a regra não dita padrões de comportamento, é apenas uma forma dos julgadores se absterem na análise da questão dos resultados durante o processo decisório no órgão regulador do mercado.

\subsection{A Business Judgment Rule no Direito Brasileiro}

A aplicação da Business Judgment Rule no direito brasileiro é recente e apoia-se no art. $159, \S 6^{\circ}$, LSA que diz "O juiz poderá reconhecer a exclusão da responsabilidade do administrador, se convencido de que este agiu de boa-fé e visando ao interesse da companhia.". A forma como a Comissão de Valores Mobiliários emprega essa regra será explorado a partir deste ponto.

$\mathrm{O}$ entendimento de que a regra norte-americana se encontra presente na legislação societária brasileira é defendida por doutrinadores como Nelson Eizirik, quando afirma:

O artigo $159, \S 6^{\circ}$, inequivocamente consagrou a business judgment rule ao proteger o administrador quando se constatar que agiu de boa-fé e visando a atingir os melhores interesses da companhia. A regra, tal como interpretada, permite ao aplicador da lei, seja na esfera judicial, seja na esfera administrativa, dar maior concretude ao standard do dever de diligência, uma vez que possibilita a sua aferição diante de casos concretos. (EIZIRIK, 2011)

No entanto, há também quem defenda que tal dispositivo legal não recepciona a regra, pois não abrange todos os seus cinco elementos, apenas a boa-fé e o interesse da companhia, conforme o entendimento de Pedro Henrique Brigagão:

No Brasil, os estudiosos da business judgment rule, em sua maioria, defendem ter sido a regra recepcionada pelo art. $159, \S 6 .^{\circ}$, da Lei 6.404/1976 (a Lei das S.A.), segundo o qual "o juiz poderá reconhecer a exclusão da responsabilidade do administrador, se convencido de que este agiu de boa-fé evisando ao interesse da companhia". Contudo, são significativas as incompatibilidades entre o texto do $\S 6 .^{\circ}$ e os elementos e características da regra norte-americana. Tanto a análise comparativa teórica quanto o estudo da prática, refletida no julgamento de casos concretos, demonstram que aquele dispositivo da Lei das S.A. em muito se diferencia da business judgment rule. Assim, afirmar que este instituto foi recepcionado por um texto com ele conflitante pode fazer com que sua aplicação sofra distorções e o afaste de seu objetivo basilar: proteger administradores que tomam decisões negociais de maneira informada, de boa-fé e no interesse da companhia. (BRIGAGÃO, 2016)

Ao se comentar a exclusão judicial de responsabilidade, há essa outra percepção do $\S 6^{\circ}$, 
do art. 159, na visão do professor Marcelo Adamek:

Há quem veja, no caso, a aplicação da business judgment rule, mas, a nosso ver, aqui a situação é outra: o juiz já avançou até o ponto de considerar o administrador culpado (ou seja, já ultrapassou as etapas de verificação da ilicitude e culpabilidade do agente, estabelecendo-as no caso concreto), mas, ainda assim, decide isentar o agente do dever de indenizar. A exclusão, portanto, ocorre a posteriori: todos os elementos do suporte fático são preenchidos, dá-se a incidência da regra e surge o dever de indenizar, mas, por intervenção do juiz, o administrador é isentado do dever de reparar o dano. (ADAMEK, 2010)

A CVM, por sua vez, muito utiliza o instituto da regra do Business Judgment Rule em seus julgados. O colegiado da autarquia, quando não aplica a regra explicitamente, o faz de forma a manter o princípio de que as deliberações dos gestores não devem ser julgadas em seu mérito, conforme apresentado nos extratos de alguns julgados:

E vai além, ainda, a Lei $n^{\circ}$ 6.404/76, que numa "tropicalização" da business judgment rule permite inclusive que se exclua a responsabilidade dos administradores, quando se verificar que estes mesmo violando a lei agiram de boa-fé e no interesse da companhia, conforme diz expressamente o parágrafo $6^{\circ}$ do art. 159 (COMISSÃO DE VALORES MOBILIÁRIOS, 2004)

'i) "note-se que o elemento normativo representa, no direito brasileiro, a incorporação da business judgment rule, tratando-se de julgamento por equidade, autorizado por lei”;

j) "Osmar Brina CORRÊA-LIMA, e.g., assevera que com o dispositivo 'o legislador de 1976 importou e implantou, no nosso ordenamento jurídico, a business judgment rule, do direito norte-americano""7 (COMISSÃO DE VALORES MOBILIÁRIOS, 2018)

“(xvii) a jurisprudência da CVM teria consagrado a aplicação da business judgement rule na análise de decisões negociais, segundo a qual, em regra, o mérito e o acerto da decisão do administrador fogem à competência do julgador/ regulador. Desde que a decisão seja tomada de boa-fé e no interesse da Companhia, considerando-se as informações, dados e circunstâncias disponíveis à época em que foi tomada, não caberá ao julgador substituir-se ao administrador;

$[\ldots]$

(xix) o Severance Package não teria sido um incentivo à demissão voluntária, pois a maioria dos colaboradores ainda continuaria na Companhia. Ainda que, posteriormente, o referido pacote não apresentasse os resultados esperados, tratar-se-ia de uma decisão equivocada, mas que teria sido tomada de boa-fé pelos administradores, considerando o que eles entendiam ser, naquele momento, o melhor interesse da HRT, razão pela qual tal decisão estaria protegida pela business judgement rule.

[...]

37. Por essas razões, ao avaliar decisões negociais tomadas por administradores de companhias abertas, o Colegiado da CVM vem adotando o padrão de revisão (standard of review) da business judgment rule (regra de decisão negocial)14 , desenvolvido a partir da jurisprudência norte-americana, cuja compatibilização com o ordenamento jurídico nacional e, em especial, com os deveres fiduciários previstos na Lei $^{\circ}{ }^{6} 6.404 / 76$, já foi confirmada pela jurisprudência 15 e pela CVM16 em diversas oportunidades" (COMISSÃO DE VALORES MOBILIÁRIOS, 
Todavia, a autarquia também profere decisões no sentido contrário à aplicação do instituto quando as decisões proferidas pelos administradores não possuem aspecto negocial, como pode ser verificado nesse extrato:

14. A business judgment rule é um dos mais importantes padrões de revisão. adotados para verificar o cumprimento dos deveres fiduciários. Em apertada síntese, a referida regra determina que as decisões negociais dos administradores sejam, a princípio, analisadas a partir do processo que o levou à decisão18, não devendo avançar em um exame de mérito.

15. Contudo, nem toda decisão tomada pelos administradores deve ser considerada uma decisão negocial. Essa categoria abrange aquelas decisões relacionadas condução dos negócios da companhia: adquirir ou alienar determinado ativo, investir ou não no desenvolvimento de um novo produto, definir o mix adequado entre capital próprio ou de terceiros, contratar ou demitir funcionários, para mencionar alguns exemplos. São decisões para as quais não existe uma resposta ótima. Nesses casos, busca-se respeitar a discricionariedade dos administradores e criar um ambiente que lhes permita assumir riscos e tomar decisões arriscadas, inovadoras e criativas sem medo de serem responsabilizados em caso de insucesso. Esse importante objetivo é alcançado pela busness judgment rule.

16. Questões diretamente relacionadas à observância de obrigações fixadas em lei, regulamento ou estatuto não são decisões negociais. Isto porque não há, nesses casos, margem de discricionariedade para decidir quanto ao cumprimento de tais obrigações. O administrador não pode alegar que uma decisão informada, refletida e desinteressada o levou a concluir pela violação do comando que estava obrigado a cumprir. Consequentemente, nessas hipóteses a análise da CVM não pode se restringir aos aspectos procedimentais. (COMISSÃO DE VALORES MOBILIÁRIOS, 2016)

Dessa forma, a autarquia vem demonstrando sua posição de concordância com a recepção da Business Judgment Rule no ordenamento jurídico brasileiro, em razão da expressa previsão legal no $§ 6$ do artigo 159 da lei de sociedades por ações.

De forma que nos casos onde é visualizado o caráter negocial da decisão administrativa, este não é esmiuçado a fim de se fundamentar a reparação para compensar o dano gerado, pelo contrário, sendo negocial e em atendimento aos requisitos vistos, ele é respeitado e mantido, e quando não atendido, pode atingir pessoalmente o administrador incauto em seus deveres profissionais. Embora ainda haja entendimento contrário, de não recepção do instituto, por muitos doutrinadores.

\section{CONCLUSÃO}

Conforme foi possível verificar, como consequência da aplicação do Business Judgment 
Rule pela Comissão de Valores Mobiliários nos litígios de responsabilidade empresariais no Brasil, encontra-se a divergência doutrinária em relação a paridade do instituto estrangeiro com a previsão na legislação societária. De um lado há quem concorde com a recepção do instituto jurisprudencial, e de outro há quem não enxergue essa paridade e a possibilidade de sua aplicação sem que haja a deturpação da regra para que esta se encaixe em nosso ordenamento positivista.

Sincronicamente, enquanto a responsabilidade civil é matéria de grande importância no meio empresarial considerando o montante do dano patrimonial que pode ser atingido pela tomada de decisões desastrosas, seja por não atentarem aos deveres legais impostos aos administradores de sociedade, seja por violarem à lei ou ao estatuto social da companhia, ou ainda por não serem fruto da primazia ao interesse da sociedade, ao caracterizar o desvio de finalidade. Há grande atenção voltada a seu estudo, no intuito de resguardar e reparar o prejuízo que a pessoa jurídica venha a sofrer, através dos atos produzidos por aqueles que formam sua voz, em decorrência de sua realidade técnica, concentrados na pessoa natural dos administradores.

Há extrema relevância na apreciação da ação de responsabilidade, onde serão examinados, não em primeiro lugar a natureza que compõe as decisões administrativas, mas o resguardo com que foram tomadas, de forma que o resultado importa em uma melhor e mais segura atuação dos gestores, que poderão escolher o que acreditam ser o melhor para a sociedade que os empossou sem o temor de terem que responsabilizar-se pessoalmente por decisões lamentáveis do ponto de vista econômico, mas seguras do ponto de vista da diligência.

A multiplicidade de exames que podem resultar da análise do comportamento de determinado administrador ao tomar uma decisão que gere dano à sociedade é tão descomunal que é sempre imprescindível a análise do caso concreto, com todas as suas particularidades. De forma que seja verificado pontualmente a presença dos requisitos que caracterizam a regra norte-americana.

A análise casuística combina a previsão legal com o entendimento dos julgadores ao votarem no órgão colegiado para solucionar de forma mais justa os inconvenientes do produto de uma decisão negocial ou não negocial.

Assim, a Comissão de Valores Mobiliários ao identificar como não negocial determinada decisão de administrador que esteja causando danos à companhia, decide pela aplicação da Business Judgment Rule como técnica de julgamento estrangeira, que possui espaço de aplicação no sistema positivista brasileiro, em razão da previsão na lei de sociedades por ações, sendo esse o entendimento da autarquia até o momento.

\section{REFERÊNCIAS}

ADAMEK, Marcelo Vieira Von. Responsabilidade civil dos administradores de S/A e as ações correlatas. São Paulo: Saraiva, 2010.

BRASIL. Lei No 10.406, de 10 de janeiro de 2002. Institui o Código Civil. Brasília, DF: 
Presidência da República, 2002. Disponível em: http://www.planalto.gov.br/ccivil_03/leis/2002/ 110406compilada.htm. Acesso em: 25 mar. 2020.

BRASIL. Lei $\mathbf{N}^{\mathbf{0}} \mathbf{6 . 3 8 5}$, de 7 de dezembro de 1976. Dispõe sobre o mercado de valores mobiliários e cria a Comissão de Valores Mobiliários. Brasília, DF: Presidência da República, 1976a. Disponível em: http://www.planalto.gov.br/ccivil_03/leis/16385.htm. Acesso em: 25 mar. 2020.

BRASIL. Lei No 6.404, de 15 de dezembro de 1976. Dispõe sobre as Sociedades por Ações. Brasília, DF: Presidência da República, 1976b. Disponível em: http://www.planalto.gov.br/ ccivil_03/leis/16404consol.htm. Acesso em: 25 mar. 2020.

BRIGAGÃO, Pedro Henrique Castello. A administração de companhias e a business judgment rule. São Paulo: Quartier Latin, 2017.

BRIGAGÃO, Pedro Henrique Castello. A business judgment rule no direito brasileiro: a problemática da recepção da regra pela lei das S.A. Revista de Direito Bancário e do Mercado de Capitais, São Paulo, SP, v. 74, 2016.

BULHÕES PEDREIRA, José Luis; LAMY FILHO, Alfredo. Direito das companhias. Rio de Janeiro: Forense, 2017.

COMISSÃO DE VALORES MOBILIÁRIOS. Decisão proferida por maioria de votos pelo Colegiado da CVM no julgamento, em 12/02/2004, do processo administrativo sancionador CVM n' 03/02 - Comissão de Inquérito. Rio de Janeiro, RJ: CVM, 2004. Disponível em: http://www.cvm.gov.br/export/sites/cvm/sancionadores/sancionador/anexos/2004/20040212_ PAS_0302.pdf. Acesso em: 25 mar. 2020.

COMISSÃO DE VALORES MOBILIÁRIOS. Extrato da sessão de julgamento do processo administrativo sancionador CVM $\mathbf{n}^{\circ}$ RJ 2013/11703. Rio de Janeiro, RJ: CVM, 2013. Disponível em: http://www.in.gov.br/materia/-/asset_publisher/Kujrw0TZC2Mb/content/ id/47539622/do1-2018-10-29-extrato-da-sessao-de-julgamento-do-processo-administrativosancionador-cvm-n-rj2013-11703-47539521. Acesso em: 25 mar. 2020.

COMISSÃO DE VALORES MOBILIÁRIOS. Extrato da sessão de julgamento do processo administrativo sancionador CVM n ${ }^{\circ}$ RJ 2016/7190. Rio de Janeiro, RJ: CVM, 2016. Disponível em: http://www.cvm.gov.br/export/sites/cvm/sancionadores/sancionador/ anexos/2018/RJ20167190_COMPLETO.pdf. Acesso em 25 de mar. 2020.

COMISSÃO DE VALORES MOBILIÁRIOS. Relatório no 130/2018-CVM/SEP. Rio de Janeiro, RJ: CVM, 2018. Disponível em: http://www.cvm.gov.br/export/sites/cvm/decisoes/ anexos/2018/20180821/1114.pdf. Acesso em: 25 mar. 2020.

EIZIRIK, Nelson. A lei das S/A comentada. São Paulo: Quartier Latin, 2011.

INSTITUTO BRASILEIRO DE GOVERNANÇA CORPORATIVA - IBGC. O que é governança corporativa. Disponível em: https://www.ibgc.org.br/conhecimento/governancacorporativa. Acesso em: 25 mar. 2020.

MARTINS, Fran. Curso de direito comercial. 40. ed. Rio de Janeiro: Forense, 2017. 
Como citar: SANTOS, Laura Soares Miranda; SANT'ANNA, Leonardo da Silva. Deveres e responsabilidades dos administradores de sociedades anônimas e o business judgment rule no Brasil. Scientia luris, Londrina, v. 25, n. 3, p. 10-24, nov. 2021. DOI: 10.5433/21788189.2021v25n3p10. ISSN: 2178-8189.

Recebido em 2020-03-25

Aprovado em 2021-07-28 